\title{
OS CONTRATOS COLIGADOS E SUA SISTEMÁTICA INTEPRETATIVA
}

\section{THE ASSOCIATED CONTRACTS AND ITS INTERPRETATIVE SYSTEMS}

NEIMAR BATISTA

Advogado na área de Direito Civil Empresarial, Graduado em Direito pela Pontifícia Universidade Católica do Paraná, Especialista em Direito Civil Empresarial pela Pontifícia Universidade Católica do Paraná, Legal Law Master - IBMEC, Mestre em Direito Civil Empresarial pela Faculdade de Direito da UNICURITIBA, Doutorando em Direito Civil pela Pontifícia Universidade Católica de São Paulo, Professor dos Cursos de Pós-Graduação da Academia Brasileira de Direito Constitucional. neimar@batistaetawil.com.br

\section{ANA ROSA TENÓRIO DE AMORIM}

Advogada na área de Direito Empresarial. Mestre em Direito Público pela Universidade Federal de Pernambuco. Doutoranda em Filosofia do Direito pela Pontifícia Universidade Católica de São Paulo. anartam@me.com

\section{A COMPLEXIDADE DAS RELAÇÕES CONTRATUAIS E SUAS DIFICULDADES HERMENÊUTICAS}

As relações contratuais, a exemplo do que ocorre com as demais relações da pós-modernidade, tornam-se cada vez mais complexas e cheias de nuances. Os instrumentos contratuais de há muito deixaram de representar contratos típicos, com 


\section{Personalidade Acadêmica Homenageada:}

Florisbal de Souza Del'Olmo (Professor Convidado - UNICURITIBA)

estipulações puras, para apresentarem um feixe de negócios jurídicos, estipulados num único ou em vários instrumentos contratuais.

Assim, as simples relações de consumo passam a apresentar não apenas um contrato de compra, mas também operações financeiras atreladas, com estipulações para cessões de crédito. Nas relações entre as empresas, sobretudo em empreendimentos de grande escala, instrumentos financeiros sofisticados, usados em casos de Project finance, exigem a constituição de instrumentos vários, tais como o de financiamento propriamente dito, as garantias oferecidas, os contratos de seguro atrelados, todos tendo como norte o elemento econômico a conferir unidade aos negócios celebrados.

Contratos típicos, como o de distribuição de bens, juntam-se a contratos de cessão de marca, e até mesmo de locação, e passam, igualmente, a formar uma nova categoria jurídica.

Esse fenômeno, chamado por Claudia Lima Marques de contratos conexos, dos quais a coligação contratual seria espécie, gera uma série de dificuldades hermenêuticas, tanto para as partes, como para o operador do direito.

A primeira dificuldade está em qualificar essas relações, em identificar se um determinado feixe de negócios jurídicos constitui uma situação de coligação contratual. O posicionamento jurisprudencial não é uníssono a respeito dos elementos constitutivos da coligação, tampouco define com muita clareza quais os efeitos decorrentes dessa qualificação.

A segunda dificuldade está em interpretar as disposições de cada negócio jurídico em particular, cotejando-as com os demais negócios jurídicos constituintes da coligação. Por fim, uma terceira dificuldade está na harmonização dos diversos instrumentos legais incidentes sobre a coligação.

O presente artigo visa apresentar uma sistemática interpretativa para o fenômeno da coligação contratual, oferecendo um ferramental metodológico que possa servir para orientar os esforços hermenêuticos das partes e dos magistrados, quando diante de situações de coligação. 


\section{Personalidade Acadêmica Homenageada: \\ Florisbal de Souza Del'OImo (Professor Convidado - UNICURITIBA)}

De início, far-se-á uma breve descrição da evolução das relações negociais para, em seguida, definir e classificar os contratos coligados, distinguindo-os de categorias semelhantes. Por fim, apresentar-se-á um modelo lógico-sistemático de interpretação o qual, sem cair num formalismo hermético, pode ajudar o intérprete a superar as dificuldades hermenêuticas apontadas acima.

\section{EVOLUÇÃo DAS RELAÇÕES NEGOCIAIS E SURGIMENTO DE NOVAS CATEGORIAS}

A natural evolução das relações negociais fez com que o principal instrumento para garantir a circulação natural de riquezas, que é o contrato nas suas mais variadas formas e modalidades ${ }^{1}$, evoluísse na sua concepção, nos seus efeitos, na sua forma de interpretação, mas principalmente na sua apresentação.

A velha concepção de que as relações jurídicas contratuais privadas irradiavam efeitos somente entre as partes (princípio da relatividade) já não encontra ressonância nos novos princípios e cláusulas abertas aplicadas ao ordenamento civil, quer sob a égide de uma interpretação civil constitucional, quer sob o modelo oriundo de um arquétipo pós-positivista, neopositivista, ou ainda, pós-moderno do sistema jurídico.

Sobre esse período, dito pós-moderno, e sobre a princípio crítica que se faz à insegurança jurídica e instabilidade causada, busca-se o apoio nas lições de Rogério Donnini:

Se os valores da modernidade estavam vinculados às ideias de estabilidade, permanência, ordenação, racionalidade, certeza e disciplina, entre outros, a pós-modernidade nos leva, definitivamente, a um confronto

\footnotetext{
1 "Entretanto, tem-se que reconhecer-se que, no âmbito dos diversos sistemas jurídicos, o contrato é em geral um instrumento legal, mas não o único instrumento legal da circulação da riqueza: no ordenamento italiano, por exemplo, também o mecanismo da sucessão mortis causa - seja testamentária seja legítima - realiza uma transferência típica de riqueza de forma não contratual; e transferência de riqueza de forma não contratual realiza, também, entre particulares e o ente público, por exemplo, o mecanismo da tributação." (in ROPPO, Enzo. O contrato. Lisboa: Editora Almedina, 2009, p. 18)
} 


\title{
Personalidade Acadêmica Homenageada: \\ Florisbal de Souza Del'OImo (Professor Convidado - UNICURITIBA)
}

\begin{abstract}
com esses ideais, pois nos deparamos, bem de ver, com a transitoriedade, mutabilidade, probabilidade, senso comum, liquidez, volatilidade, relatividade e sensibilidade. As diferenças entre os pensamentos desses dois períodos são evidentes quando se constata que na modernidade o raciocínio é unívoco, lógico, demonstrativo e normativo, enquanto na pósmodernidade, contrariamente, o discurso é plurívoco, flexível, móvel. ${ }^{2}$
\end{abstract}

Nota-se, pois, que os princípios sobre os quais se formou nosso atual ordenamento privado, baseados na eticidade, socialidade e operabilidade ${ }^{3}$, dotam o juiz, nas hipóteses de intervenção no contrato, de um poder que, por muitos, é considerado exacerbado, causando instabilidade e insegurança jurídica.

É verdadeira a afirmação de que os contratos não convivem bem com esse ambiente de insegurança jurídica, todavia, também é verdade a assertiva de que esse fundamental instrumento deva espelhar o modelo jurídico que lhe impõe a sociedade. A visão de operações econômicas, que pode compreender um contrato sob a ótica individual ou unitária (contratos simples ou mistos), assim como sob a vertente da pluralidade de contratos (redes contratuais, contratos coligados ou complexos), é um fenômeno que demanda a interpretação do jurista e, por vezes, uma análise por demais detalhada e aprofundada, dado o emaranhado de repercussões possíveis na esfera das partes e, em certos casos, na sociedade como um todo.

Nessa concepção, como o intuito do presente trabalho é o foco interpretativo dos contratos coligados, necessário se faz uma digressão acerca das causas que levaram à conjugação desses instrumentos, além, é claro, da evolução da autonomia das partes em criar e modificar as relações privadas.

Não se busca aqui, obviamente, esvair o tema dos contratos coligados ou das redes contratuais, mas sim uma alternativa à sua interpretação sob o viés jusfilosófico, de modo a dirimir certas dúvidas que ainda pairam nessa modalidade de contratação, quer devido à sua complexidade ou enquadramento legislativo duvidoso.

\footnotetext{
2 DONNINI, Rogério. Responsabilidade civil na pós-modernidade: felicidade, proteção, enriquecimento com causa e tempo perdido. Porto Alegre: Sérgio Antônio Fabris Ed., 2015, p. 17-18.

${ }_{3}^{3}$ Conforme retro anunciado, respectivamente contempladas, nos artigos 113 e 422, 187, 421 e 2.035do Codex.
} 


\section{Personalidade Acadêmica Homenageada: \\ Florisbal de Souza Del'OImo (Professor Convidado - UNICURITIBA)}

Há que se esclarecer, prima facie, que o tema será tratado sob o viés da autonomia privada, conceito já bastante evoluído nas relações civis, e que não tira das partes a opção de contrair obrigações livremente, ou ainda, de estabelecê-las na medida de suas necessidades e interesses, mas impõe o dever de velar pelo respeito aos Princípios Gerais do Direito, bem como pelos reflexos que podem impor à sociedade ${ }^{4}$. Assim, os contratos, suas aplicações, a extensão de seus efeitos entre as partes e perante terceiros, a forma como que se apresentam, tomaram uma nova vertente ao se aplicar normas de conteúdo aberto, das quais, em grande parte, decorrem as próprias coligações, como no caso das relações trabalhistas ou no direito consumerista.

Sob essa ótica, as cláusulas abertas da boa-fé ${ }^{5}$, função social, vedação ao abuso de direito, servem como cânone de interpretação e conduta nas relações, ditas, coligadas ou complexas, além, é claro, de permitir uma maior extensão de seus efeitos em relação entre às partes.

As relações entre empresas, principalmente, envolvendo indústrias e seus fornecedores, e entre aquelas e seus distribuidores, representantes comerciais, ou mesmo, franquias, para expressar seu modelo de marketing, sua filosofia de mercado, divulgar sua marca e seus produtos, demandam uma série de contratos que nem sempre envolvem um conceito jurídico único ou, até mesmo, as mesmas partes. Além disso, relações em que há vulnerabilidade do contratante ou onde haja a necessidade de interpretação conjunta dos instrumentos contratuais envolvidos para se tutelar o hipossuficiente, como é o caso das relações de consumo e de trabalho, demandam noções e balizas teóricas interpretativas.

\footnotetext{
4 "Sem qualquer dúvida, o princípio da autonomia da vontade é um princípio existente no direito civil, mas que perdeu espaço atualmente para a autonomia privada que possui uma concepção muito mais elaborada, com esteio na teoria do negócio jurídico, entendendo-se esta como o verdadeiro fundamento para a possibilidade de firmarem-se normas jurídicas individuais. "NANNI, Giovanni Ettore. A evolução do direito civil obrigacional: A concepção do direito civil constitucional e a transição da autonomia da vontade para a autonomia privada. In Cadernos de Direito Civil Constitucional. Renan Lotufo (coord.). $1^{\underline{a}}$ ed. (2001) 8를 reimpressão. Curitiba: Juruá, 2008, p. 168.

${ }^{5}$ Falar na atualidade na diferenciação entre boa-fé objetiva e subjetiva ${ }^{5}$ parece um tanto quanto irrelevante quando se está abordando a boa-fé sob o ponto de vista de standard de conduta nas relações obrigacionais.
} 


\title{
Personalidade Acadêmica Homenageada: \\ Florisbal de Souza Del'OImo (Professor Convidado - UNICURITIBA)
}

Claudia Lima Marques adota a expressão contratos conexos para delinear os ditos contratos coligados, enfatizando a importância da interpretação da conexidade contratual nas relações de consumo em relação ao chamado clientecativo $^{6}$ :

\begin{abstract}
A visão da conexidade contratual das operações econômicas intermediárias e anexas ao consumo complexo de produtos e serviços dos dias hoje é uma necessidade. Os contratos conexos são aqueles cuja finalidade é justamente facilitar ou realizar o consumo. $O$ aplicador do CDC deve estar atento para o fenômeno da conexidade, pois a uma visão real e socialmente útil da multiplicidade e complexidade das relações contratuais pósmodernas pode-se apor uma visão formalista e reduzida, a impedir a realização da função social dos contratos. Mister, portanto, ao analisar as relações cativas e de longa duração, analisar também os chamados "atos de consumo por conexidade" ou relações de consumo acessórias, que também podem durar no tempo e ser instrumentos de fática catividade de consumidores, apesar de pontuais. ${ }^{7}$
\end{abstract}

O contrato deixa de ter o viés de conceito jurídico para identificar operações econômicas complexas que, na visão de Roppo, podem resumir todas as situações, as relações e os interesses que constituem a substância de qualquer contrato ${ }^{8}$, ou seja, desde sua concepção à sua execução e solução de conflitos.

As operações econômicas ganham força e merecem amparo pela doutrina jurídica, em especial no que diz respeito à sua classificação e operacionalidade, possibilitando ao intérprete uma visão interligada de direitos e obrigações, principalmente em relações onde se vislumbra o reconhecimento legal da vulnerabilidade de um dos envolvidos, como é o caso das relações e consumo e dos contratos de trabalho. Situações como essas, ditas complexas, eis que não raras vezes se manifestam por uma ou mais espécies de contrato, ou até mesmo expressando em um só instrumento várias modalidades de contrato previstas em

\footnotetext{
${ }^{6}$ No contexto, cliente cativo reflete a cadeia de relações negociais complexas entre fornecedores, distribuidores de produtores e serviços que vinculam o consumidor por longos períodos de duração.

${ }^{7}$ MARQUES, Claudia Lima. Contratos no Código de Defesa do Consumidor: o novo regime das relações contratuais. 5a ed. São Paulo: Editora Revista dos Tribunais, 2005, p. 105.

${ }^{8}$ ROPPO, Enzo. 0 contrato. Lisboa: Editora Almedina, 2009, p. 08.
} 


\section{Personalidade Acadêmica Homenageada: \\ Florisbal de Souza Del'Olmo (Professor Convidado - UNICURITIBA)}

lei ${ }^{9}$, representam legítima expressão da autonomia privada, autorizada pelo ordenamento civil brasileiro em seu artigo 425.

O direito é uma ciência em constante mutação, deve se espelhar na realidade e em suas necessidades, sob pena de ser por esta superado ${ }^{10} \mathrm{e}$, sendo $\mathrm{o}$ contrato o meio pelo qual se busca a segurança jurídica na circulação de riquezas, nada mais correto que as operações econômicas por ele protegidas, também se pautem pelas mudanças impostas pela evolução social. É certo que o sistema jurídico atual, ainda que sob a égide das cláusulas abertas aplicadas à sua interpretação, sofre críticas por ser extremamente vago, e o modelo do Estado-Juiz, como vem sendo chamado pela sociedade pós-moderna, sem parâmetros para balizar essas situações, acaba por comprometer a segurança jurídica das operações econômicas ${ }^{11}$.

Demanda-se, assim, a necessária classificação dessas modalidades de operações econômicas, que é objeto do tópico seguinte.

\section{DEFINIÇÃO, CLASSIFICAÇÃO E ESPÉCIES DE CONTRATOS COLIGADOS OU REDES CONTRATUAIS}

$\mathrm{Na}$ acepção teórica da matéria é importante situar o tema dentro da classificação geral dos contratos, extraindo daí suas espécies. Nessa ordem, necessário primeiramente dedicar atenção à expressão "contratos complexos", de

\footnotetext{
${ }^{9}$ Exemplo: Locação de Imóveis e fiança locatícia, cédula de crédito e aval, cessão de marca e locação de equipamentos, etc.

${ }^{10}$ No dizer de Georges Ripert: "Quando o Direito ignora a realidade, a realidade se vinga ignorando o Direito".

${ }^{11} \mathrm{Já}$ se constatou que as normas gerais e abstratas não mais atendem à sociedade complexa. Essa sociedade criou um grande número de situações peculiares que passaram a exigir regras especiais de forma objetiva e detalhada em razão de seu grande número, de sua capacidade de mutação e do surgimento de novas situações. Observou-se, também, que o modelo de normas recheadas de conceitos vagos e indeterminados, que deixa as questões para serem resolvidas pelo Poder Judiciário com grande discricionariedade, é inadequado em razão da insegurança jurídica que gera. Deve-se ressaltar, sobretudo, a incapacidade do Judiciário de atender a todas as demandas. MIGUEL, Paula Castello. Contratos entre empresas. São Paulo: Editora Revista dos Tribunais, 2006, p. 89.
} 


\section{Personalidade Acadêmica Homenageada: \\ Florisbal de Souza Del'OImo (Professor Convidado - UNICURITIBA)}

modo a seguir daí para o delineamento dos contratos coligados ou, ainda, redes contratuais ou contratos conexos.

Toda a relação complexa tem o potencial de atrair contratos mistos ou coligados, mas com ela não se confunde. Por contrato complexo temos aquela relação na qual ao menos uma das partes realiza uma pluralidade de obrigações, ou ainda, em que as obrigações de uma das partes correspondam a tipos contratuais distintos ${ }^{12}$.

Muito embora haja autores que defendem tratar os contratos coligados e os mistos como espécie autônoma, entendo ser mais adequado relacionar essas modalidades contratuais como subespécies dos contratos complexos, o que, aliás, é tratado como sinônimo por alguns doutrinadores, como no caso de Cláudia Lima Marques, ao se referir à posição dos consumidores nas redes contratuais ${ }^{13}$. Necessário, porém, diferenciar os contratos mistos dos contratos coligados, eis que aqueles, apesar de combinar elementos de diversos contratos, não formam uma nova espécie contratual, diferente do que ocorre nos contratos coligados ${ }^{14}$.

Como exemplo dos contratos mistos, tem-se a locação de imóveis com garantida por fiança ou caução, que resumem num só instrumento duas espécies contratuais (locação de imóveis e fiança/caução), ou ainda, o contrato de compra e venda de imóvel com garantia hipotecária (venda e compra e garantia hipotecária), todos esses representados em um único instrumento, sem compreender partes

\footnotetext{
12 MARINO, Francisco de Paula De Crescenzo. Contratos Coligados no direito brasileiro. São Paulo: Saraiva, 2009, p. 111.

${ }^{13}$ Estes novos contratos complexos envolvendo fazeres na sociedade representam o novo desafio da teoria dos contratos. São serviços prestados por um fornecedor ou por uma cadeia de fornecedores solidários, organizados internamente, sem que o consumidor, na maioria das vezes, fique consciente desta organização. Trata-se de serviços que no contexto da vida moderna, de 'grande insegurança e de indução através da publicidade massiva à necessidade de acumulação de bens materiais e imateriais (o chamado 'poder da necessidade' e a 'sedução das novas necessidades'), vinculam o consumidor de tal forma que, ao longo dos anos de duração da relação contratual complexa, torna-se este 'cliente-cativo' daquele fornecedor ou cadeia de fornecedores, tornando-se dependente mesmo da manutenção daquela relação contratual ou verá frustradas todas as suas expectativas. Em outras palavras, para manter o vínculo com o fornecedor aceitará facilmente qualquer nova imposição por este desejada. MARQUES, Cláudia Lima. Contratos Bancários em tempos pós-modernos - primeiras reflexões. Revista de Direito do Consumidor, São Paulo: Ed. Revista dos Tribunais, 1998, v. 25, p. 19-38, jan/mar, 1998, pág. 25.

${ }^{14}$ GOMES, Orlando. Contratos. Rio de Janeiro: Forense, 1998, p. 105
} 


\section{Personalidade Acadêmica Homenageada: \\ Florisbal de Souza Del'OImo (Professor Convidado - UNICURITIBA)}

diferentes, como ocorre nos contratos coligados, quando geralmente há mais de uma parte envolvida, por meio de vários instrumentos contratuais.

No que tange à coligação contratual, pode ser definida como um gênero em que duas ou mais diferentes espécies contratuais estão vinculadas de modo a promover alguma eficácia paracontratual ${ }^{15}$, cuja união, segundo a classificação de Enneccerus, apresentada por Orlando Gomes, podem ser meramente externa, com dependência, ou alternativa ${ }^{16}$.

A primeira hipótese (coligação externa) é tratada como meramente instrumental, em que as partes reúnem num mesmo instrumento obrigações coligadas, sem que haja interdependência entre contratos, por ato externo na sua conclusão, hipótese que não configura exatamente a coligação. Na união com dependência, as partes entabulam dois ou mais contratos, subordinando a existência de um à manutenção de outro, considerando-se estes os mais próximos dos contratos mistos, dos quais diferenciam-se pelo fato de expressar-se em dois ou mais instrumentos, mas, todavia, configurando uma única operação econômica. Essa dependência pode ser bilateral ou unilateral, na medida em que dependam um do outro de forma recíproca ou não.

A última hipótese, que é a união alternativa, há previsão no sentido de que subsista um ou outro contrato, ou seja, concretizada uma condição, extingue-se o outro, diferenciando-se, portanto, da relação de dependência, onde um contrato não existe sem o outro.

Já Francisco Paulo de Crescenzo Marino classifica os contratos coligados em legal ou ex lege, natural e coligação voluntária ${ }^{17}$. A modalidade ex lege é citada por Cláudia Lima Marques nas relações de crédito e serviço ao consumidor, contida na regra do artigo 52 e o art. $3^{\circ}$, parágrafo $2^{\circ}$ do CDC, ou seja, a coligação ou

\footnotetext{
${ }^{15}$ LEONARDO, Rodrigo Xavier, Contratos coligados, redes contratuais e contratos conexos. In: FERNANDES, Wanderley (coord). Contratos Empresariais: fundamentos e princípios dos contratos empresariais. São Paulo: Saraiva, 2012, pág. 351.

${ }^{16}$ GOMES, Orlando. Contratos. Rio de Janeiro: Forense, 1998, p. 104.

17 MARINO, Francisco de Paula De Crescenzo. Contratos Coligados no direito brasileiro. São Paulo: Saraiva, 2009, p.100.
} 


\section{Personalidade Acadêmica Homenageada:}

Florisbal de Souza Del'Olmo (Professor Convidado - UNICURITIBA)

conexidade do contrato são determinadas pela $\operatorname{Lei}^{18}$. A coligação natural, por sua vez, é aquela em que a coligação decorre da própria natureza acessória típica de um dos contratos envolvidos na coligação, como, por exemplo, nos contratos de empreitada para construção de obras, onde já se antevê a necessidade de subempreitada de determinadas atividades, que necessita de mão de obra específica ${ }^{19}$.

Finalmente, há coligação voluntária quando o nexo entre os contratos não deriva da lei ou da natureza acessória do contrato, mas sim da expressa manifestação das partes nos próprios instrumentos contratuais, por meio de cláusulas que condicionem a eficácia de um contrato a outro ${ }^{20}$.

Por fim, mas não menos importante, cabe menção à classificação feita por Claudia Lima Marques ao que denomina contratos conexos (sinônimos a coligados), delimitando-os em "grupos de contratos", em que vários contratos concorrem para um mesmo fim, "rede de contratos", nas quais cada contrato tem por objeto sucessivamente as mesmas coisas, mesmo serviços e mesmo objeto de prestação, e "contratos conexos stricto sensu", que são aqueles celebrados pelas mesmas partes ou partes diferentes, que se vinculada por uma finalidade econômica supracontratual comum. ${ }^{21}$

Não obstante as várias classificações impostas pela doutrina, importa salientar que os contratos coligados ou redes contratuais se expressam nas mais variadas situações, quer seja envolvendo relações paritárias, ou ainda, relações em que haja hipossuficiência entre os contratantes. Enfim, essa modalidade de interpretação de contratos se mostra extremamente útil para o pleno exercício dos efeitos que as operações econômicas irradiam no mercado. Todavia, o viés interpretativo dessas relações complexas precisa ser cada vez mais aperfeiçoado, conforme será demonstrado pela aplicação dada pelos tribunais a esse tipo de relação contratual.

\footnotetext{
${ }^{18}$ MARQUES, Claudia Lima. Contratos no Código de Defesa do Consumidor: o novo regime das relações contratuais. 5a ed. São Paulo: Editora Revista dos Tribunais, 2005, p. 107.

${ }^{19}$ Conf. MARINO, op cit, p. 105-106.

${ }^{20}$ Conf. MARINO, op cit. p. 107-108.

${ }^{21}$ Conf. MARQUES, op. cit., p. 105-107.
} 


\section{Personalidade Acadêmica Homenageada:}

Florisbal de Souza Del'Olmo (Professor Convidado - UNICURITIBA)

\section{APLICAÇÕES DESSAS NOVAS CATEGORIAS CONTRATUAIS NOS MEIOS EMPRESARIAIS E A VISÃO DO JUDICIÁRIO}

As modalidades contratuais coligadas estão presentes no cotidiano tantos das pessoas quanto das empresas, revelando uma maneira adequada de interpretar as operações econômicas e seus reflexos. Assim são as relações de distribuição mercantil, que envolvem o contrato de distribuição propriamente dito, um contrato de cessão de marca, um contrato de compra e venda de produtos com o consumidor final, que geralmente está atrelado à assistência técnica, em se tratando de produtos duráveis, que obriga não só o distribuidor, mas também o fabricante.

Essa situação é bem visível na distribuição de combustível, em que um instrumento estabelece a exclusividade do distribuidor, seus direitos e deveres, com estipulação de cota mínima na aquisição de combustíveis e produtos, havendo outros instrumentos para a locação do imóvel onde irá se situar o estabelecimento, às vezes firmado pela própria companhia com a sublocação para o distribuidor. Há, ainda, a cessão da marca, o fornecimento em comodato de equipamentos e logotipos, a figura concessão ou franquias de lojas de conveniência, etc.

Igualmente coligados são os contratos de contratos cessão de mão de obra e respectivos contrato de trabalho, eis que sob a ótica do empregado, mesmo para efeitos legais, irradiam-se obrigações não só para o contratante direto (empregador), mas também para o vínculo indireto do contratante da mão de obra.

No contrato de transporte urbano, rodoviário e aéreo, em que estão vinculados o poder concedente, a concessionária e o consumidor final, há também a interpretação coligada, havendo decisões judiciais que entendem legítimas para responder pela indenização tanto a concessionária quanto a empresa pública concedente $^{22}$.

\footnotetext{
${ }^{22}$ Cf. TJPR - 2ª C.Cível - Al - 164695-5 - Londrina - Rel.: Bonejos Demchuk - Unânime - J. 23.02.2005) - fonte https://portal.tjpr.jus.br/jurisprudencia///1433164/Ac\%C3\%B3rd\%C3\%A3o164695-5\#, acesso em 24/04/2017.
} 


\section{Personalidade Acadêmica Homenageada: Florisbal de Souza Del'OImo (Professor Convidado - UNICURITIBA)}

Também em relações contratuais mais complexas, envolvendo por vezes contratos internacionais, que compreendem a formação de consórcio de empresas para realização de obras de grande monta, ou ainda, formado joint ventures para a realização de financiamentos a operações ou criação de fundos de investimentos, aparece a figura da coligação. Um caso bastante emblemático de coligação contratual tratado pelo Superior Tribunal de Justiça é o em que se discute o fornecimento, intermediação e aquisição de gás natural entre a cadeia de fornecimento e uma termoelétrica, tendo uma das componentes da cadeia fixado individualmente o preço. Nesse caso, muito embora reconhecida a conexão da relação havida em sentença arbitral, entendeu o Superior Tribunal de Justiça poder haver independência de uma das relações, em especial na fixação do preço ao consumidor final do gás ${ }^{23}$.

\footnotetext{
23 “(....) A indiscutível coligação e conexão entre os contratos celebrados, para o fornecimento, intermediação e aquisição de gás natural, a evidenciar, portanto, o nexo de funcionalidade dos ajustes, não subtrai a autonomia e a individualidade da relação jurídica inserta em cada contrato, com partes e objetos próprios. Por contratos coligados compreende-se a celebração de dois ou mais contratos autônomos, mas que guardam entre si um nexo de funcionalidade econômica, a propiciar a consecução de uma finalidade negocial comum.2.1 $\mathrm{O}$ objeto da ação promovida pela Termopernambuco em face da Copergás, perante o Centro Brasileiro de Mediação e Arbitragem, consiste em saber se a Copergás, ao proceder ao aludido repasse de valores por ocasião da revenda do gás natural à Termopernambuco, infringiu ou não a cláusula que estipulou o preço no contrato entre elas estabelecido (GSA downstream), parda a aquisição de gás natural. O "preço" nada mais é do que a própria obrigação contratual assumida pela Termopernambuco no âmbito do GSA downstream. Por consectário, a composição do preço pelo qual a Termopernambuco adquire gás natural da Copergás é matéria necessariamente disciplinada no mencionado ajuste (GSA downstream) e, por óbvio, enseja a vinculação somente das partes contratantes.2.2 Não se olvida que a consecução do negócio econômico em comum, perseguido pelas partes e viabilizado pela coligação dos contratos, depende, naturalmente, do cumprimento das obrigações contratuais de todos os envolvidos, no bojo dos respectivos ajustes. Indiscutível, nessa medida, que as partes de cada relação contratual tenham reciprocamente interesses jurídico e econômico quanto à perfectibilização dos ajustes como um todo. Essa circunstância, todavia, não torna um dos contratantes titular dos direitos e obrigações discutidos no bojo do outro contrato coligado.2.3 A partir da delimitação do objeto da contenda arbitral, pode-se antever com segurança que o provimento de mérito perseguido na arbitragem, independente de seu desfecho, não teria o condão de repercutir diretamente na esfera jurídica da Petrobrás, que, é certo, não titulariza a relação jurídica representada pelo contrato GSA downstream. Por consectário, não se haveria de cogitar, igualmente, que o provimento arbitral regularia de modo uniforme a situação jurídica dos supostos litisconsortes (a Copergás e a Petrobrás). 3 . Seja pela fluência do prazo decadencial da ação anulatória para infirmar o comando exarado na sentença parcial arbitral, seja principalmente pela não conformação de litisconsórcio passivo necessário e unitário a ser integrado pela Petrobrás no âmbito da arbitragrem, dá-se provimento ao presente recurso especial, para reconhecer a validade da sentença arbitral definitiva no tocante à delimitação subjetiva da arbitragem, determinando-se, por conseguinte, a remessa dos autos ao Tribunal de origem para prosseguir na análise dos fundamentos
} 


\section{Personalidade Acadêmica Homenageada: Florisbal de Souza Del'OImo (Professor Convidado - UNICURITIBA)}

Porém, não é essa a razão de ser dos contratos coligados, havendo que, necessariamente, se contemplar toda a operação econômica para se delinear a obrigação das partes, o que não foi observado na decisão em cotejo.

Expressam-se também na forma de contratos coligados as relações bancárias, ligando os agentes financeiros aos seus correntistas, tomadores de crédito e investidores, albergando os riscos das operações, que compreendem contatos de seguro e resseguro.

Também nessas hipóteses vêm decidindo as cortes superiores no sentido de que se anula toda a cadeia contratual na hipótese de ser constatado vício redibitório no produto objeto de financiamento. Essa situação foi também objeto de decisão do Superior Tribunal de Justiça em que, adquirida uma cozinha pré-montada que veio a apresentar defeitos, o vício comprometeu igualmente o contrato de financiamento do bem a ela vinculado ${ }^{24}$.

remanescentes, estes sim, relacionados à sentença arbitral final.(REsp 1519041/RJ, Rel. Ministro MARCO AURÉLIO BELLIZZE, TERCEIRA TURMA, julgado em 01/09/2015, DJe 11/09/2015)"

${ }^{24}$ Recurso Especial - Ação De Rescisão Contratual De Compra E Venda Para Fabricação E Instalação De Cozinhas Planejadas Cumulada Com Repetição De Indébito - Instâncias Ordinárias Que Julgaram Procedente A Ação Para Declarar Rescindidos Os Contratos E Condenar Os Réus (Lojista, Fabricante E Banco), Solidariamente, A Devolver Aos Autores As Quantias Despendidas, Com Acréscimo De Correção Monetária E Juros Moratórios - Insurgência Da Casa Bancária Contrato Coligado Amparado Em Cessão De Crédito Operada Entre O Banco E O Fornecedor Dos Bens Em Virtude De Financiamento, Por Meio Da Qual Passou A Casa Bancária A Figurar Como Efetiva Credora Dos Valores Remanescentes A Serem Pagos Pelos Consumidores (Prestações), Deduzido O Valor Da Entrada/Sinal - Recurso Especial Conhecido Em Parte E Na Extensão, Parcialmente Provido Para Afastar A Responsabilidade Solidária Da Casa Bancária No Tocante À Integralidade Dos Valores Desembolsados Pelos Autores, Remanescendo O Dever De Restituir Os Importes Recebidos Mediante Boleto Bancário Devidamente Corrigidos E Acrescidos De Juros De Mora A Contar Da Citação Por Se Tratar De Responsabilidade ContratuaL. (...) 3. Em que pese a alegação da casa bancária de que teria formulado contrato de crédito direto ao consumidor, tal assertiva não se depreende do acervo fático delineado pelas instâncias ordinárias, denotando-se a existência de contrato coligado (compra e venda de cozinhas com pagamento parcelado na relação consumidor-lojista) amparado em cessão de crédito operada entre o banco e o fornecedor dos bens em virtude de financiamento, por meio da qual passou a casa bancária a figurar como efetiva credora dos valores remanescentes a serem pagos pelos consumidores (prestações). $3.1 \mathrm{O}$ contrato coligado não constitui um único negócio jurídico com diversos instrumentos, mas sim uma pluralidade de negócios jurídicos, ainda que celebrados em um único documento, pois é a substância do negócio jurídico que lhe dá amparo, não a forma. 3.2 Em razão da força da conexão contratual e dos preceitos consumeristas incidentes na espécie - tanto na relação jurídica firmada com o fornecedor das cozinhas quanto no vínculo mantido com a casa bancária -, o vício determinante do desfazimento da compra e venda atinge igualmente o financiamento, por se tratar de relações jurídicas trianguladas, cada uma estipulada com o fim precípuo de garantir a relação jurídica antecedente da qual é inteiramente dependente, motivo pelo qual possível a arguição da exceção de contrato não cumprido, uma vez que a posição jurídica ativa conferida ao consumidor de um produto financiado/parcelado 


\section{Personalidade Acadêmica Homenageada: Florisbal de Souza Del'OImo (Professor Convidado - UNICURITIBA)}

A operação de seguro e resseguro das companhias seguradoras também espelham uma relação coligada, limitadas, por óbvio, na relação entre essas e o consumidor final pela respectiva legislação protetiva.

Enfim, a interpretação conjunta dos instrumentos nessa modalidade de contratos se faz indispensável não só as partes, mas também ao julgado no momento da solução de conflitos, como os aqui expostos e, ainda que haja certa coerência nas decisões, constata-se a carência efetiva de modelos interpretativos. É esse o objetivo do presente trabalho, ou seja, garantir as partes ou ao próprio julgador, uma base metodológica para dirimir as questões ou litígios advindos dos contratos coligados.

relativamente à oponibilidade do inadimplemento do lojista perante o agente financiador constitui efeito não de um ou outro negócio isoladamente considerado, mas da vinculação jurídica entre a compra e venda e o mútuo/parcelamento. 3.3. Entretanto, a ineficácia superveniente de um dos negócios, não tem o condão de unificar os efeitos da responsabilização civil, porquanto, ainda que interdependentes entre si, parcial ou totalmente, os ajustes coligados constituem negócios jurídicos com características próprias, a ensejar interpretação e análise singular, sem contudo, deixar à margem o vínculo unitário dos limites da coligação. 3.4 Assim, a interpretação contratual constitui premissa necessária para o reconhecimento da existência e para a determinação da intensidade da coligação contratual, o que no caso concreto se dá mediante a verificação do animus da casa bancária na construção da coligação e o proveito econômico por ela obtido, pois não obstante o nexo funcional característico da coligação contratual, cada um dos negócios jurídicos entabulados produz efeitos que Ihe são típicos nos estritos limites dos intentos dos participantes.3.5 Inviável responsabilizar solidariamente a financeira pelos valores despendidos pelos consumidores, uma vez que, ao manter o contrato coligado, não se comprometeu a fornecer garantia irrestrita para a transação, mas sim balizada pelos benefícios dela advindos, ou seja, no caso, nos termos da cessão de crédito operada, que não abarca os valores pagos à título de entrada diretamente ao lojista.3.6 A circunstância de o contrato de financiamento sucumbir diante do inadimplemento do lojista não transforma a casa bancária em garante universal de todos os valores despendidos pelos autores, principalmente porque a repetição do indébito limita-se àquilo que efetivamente foi desembolsado seja dos consumid6ores para com a financeira, seja desta para com a lojista. A responsabilidade do banco fica limitada, portanto, à devolução das quantias que percebeu, pois, a solidariedade não se presume, decorre da lei ou da vontade das partes. 4. Recurso especial conhecido em parte e, na extensão, parcialmente provido, para afastar a responsabilidade solidária da casa bancária pela repetição integral dos valores despendidos pelos consumidores, abarcando aquele pago a título de entrada no negócio de compra das cozinhas planejadas, remanescendo a responsabilidade do banco na devolução atualizada dos valores recebidos por meio dos boletos bancários, em razão da cessão do crédito restante (crédito cedido pela lojista não abrangendo o valor recebido por esta última a título de entrada no negócio), pois as vicissitudes de um contrato repercutiram no outro, condicionando-lhe a validade e a eficácia. (REsp 1127403/SP, Rel. Ministro LUIS FELIPE SALOMÃO, Rel. p/ Acórdão Ministro MARCO BUZZI, QUARTA TURMA, julgado em 04/02/2014, DJe 15/08/2014) 


\section{Personalidade Acadêmica Homenageada:}

Florisbal de Souza Del'Olmo (Professor Convidado - UNICURITIBA)

\section{CLASSIFICAÇÃO CONTRATUAL, COERÊNCIA INTERNA DOS CONTRATOS E INTERPRETAÇÃO LÓGICO-SISTEMÁTICA}

Como ficou evidenciado na discussão jurisprudencial, a própria definição do que vem a ser a figura da coligação contratual não é muito clara na jurisprudência, ora misturando-se elementos essencialmente jurídicos, ora incluindo elementos econômicos. O primeiro passo a ser adotado para qualquer modelo de interpretação de tais figuras contratuais é estabelecer uma definição de contratos coligados para que se possa, em seguida, conseguir fazer a operação de qualificação jurídica de tais negócios.

Os conceitos jurídicos, como explica Jean-Louis Bergel ${ }^{25}$, possuem um aspecto formal e um aspecto substancial. $O$ aspecto substancial visa delimitar os elementos constituidores e como tais elementos se organizam, como se relacionam para forjar o conceito em questão. Muitas vezes essas relações são de cumulatividade, alternatividade, exclusão, causalidade, reciprocidade. ${ }^{26}$

$O$ aspecto formal tem a ver com o meio como tal conceito é enunciado, isto é, se decorre de expressa previsão legal - algo não tão frequente no direito romanogermânico - ou se decorre de construção doutrinária.

Analisando a figura dos contratos coligados, pode-se utilizar a definição exposta por Francisco Marino ${ }^{27}$ :

Contratos coligados podem ser conceituados como contratos que, por força de disposição legal, da natureza acessória de um deles ou do conteúdo contratual (expresso ou implícito), encontram-se em relação de dependência unilateral ou recíproca.

A definição de Marino pode ser melhor destrinchada. O fenômeno da coligação contratual está relacionado com a dependência unilateral ou recíproca do conteúdo contratual, sendo este o principal traço distintivo desse conceito. As

\footnotetext{
${ }^{25}$ BERGEL, Jean-Louis. Teoria Geral do Direito. São Paulo: Martins Fontes, 2001, p.255.

${ }^{26}$ Cf. BERGEL, Jean-Louis, op. cit., 258.

${ }^{27}$ MARINO, Francisco Paulo de Crescenzo. Contratos coligados no Direito Brasileiro. São Paulo: Saraiva, 2009, p. 99.
} 


\section{Personalidade Acadêmica Homenageada: \\ Florisbal de Souza Del'Olmo (Professor Convidado - UNICURITIBA)}

matérias dos contratos - o que engloba também o aspecto econômico, mas não só este - precisam estar em relação de dependência. Em alguns casos, a dependência é estabelecida pela própria lei, de modo que se tem uma coligação ex lege; noutros casos, a dependência decorre da acessoriedade, de modo que não precisa conter uma manifestação expressa sobre a coligação; por fim, a dependência decorre do conteúdo contratual e vem explicitada ou não pelas partes. Esquematicamente, pode-se estabelecer que os contratos coligados têm como elemento principal a dependência unilateral ou recíproca (E1), podendo esta decorrer implicitamente da acessoriedade (E2) ou de disposição legal (E3). Apenas o elemento (E1), nesse esquema, seria essencial:

Gênero:

a) Contratos coligados voluntários: que exigem dependência unilateral ou recíproca $(\mathrm{E} 1)$;

Espécies:

b) Contratos coligados naturais: contratos que exigem dependência unilateral ou recíproca decorrente da acessoriedade $(\mathrm{E} 1+\mathrm{E} 2)$; c) Contratos coligados ex lege: contratos que exigem dependência unilateral ou recíproca estipulada por lei $(\mathrm{E} 1+\mathrm{E} 3)$.

Observe-se que a relação entre os elementos é de cumulatividade para os pares (E1; E2) e (E1; E3), mas basta o elemento (E1), isto é, a dependência unilateral ou recíproca, para configurar um contrato coligado. De posse desse conceito, o operador categoriza o direito, distinguindo-o de outras situações semelhantes, e pode realizar a operação da qualificação jurídica. No dizer de JeanLouis Bergel:

A definição dos conceitos se prolonga, de fato, na categorização deles. Então já não se trata de estudar cada fenômeno jurídico em si, mas de compará-lo aos outros para aproximá-los ou dissociá-los deles. Cumpre agrupar numa mesma categoria, submetida a determinado regime, as entidades mais profundamente semelhantes e separar em categorias diferentes, dotadas de regras diferentes, entidades essencialmente dessemelhantes. 


\section{Personalidade Acadêmica Homenageada: \\ Florisbal de Souza Del'OImo (Professor Convidado - UNICURITIBA)}

De acordo com o jurista Orlando Gomes, "as categorias são os quadros em que se agrupam, por afinidade, os elementos da vida jurídica"28. Assim, muito embora se trabalhe hodiernamente com modelos mais fluidos, em que os sistemas jurídicos são considerados sistemas abertos e adotam estruturas mais flexíveis como as cláusulas gerais e os conceitos jurídicos indeterminados, não se pode abandonar os instrumentos da técnica do Direito, uma vez que esses instrumentos estruturam e organizam os diversos elementos jurídicos. Tais elementos, acaso largados à própria sorte, careceriam de sistematicidade. Sendo o ordenamento jurídico um sistema aberto, este até pode prescindir, como advoga Cannaris, da completude - daí sua abertura - mas não da unidade e da ordem. ${ }^{29}$ Os conceitos e categorias jurídicas, como elementos da técnica jurídica, vêm para atender a exigência de ordenação e estrutura dos sistemas jurídicos, quer se os considerem abertos, como se faz no presente trabalho, quer se os considerem fechados.

Após o estabelecimento de uma definição para um determinado conceito jurídico, o passo seguinte seria sua categorização, ensejando, como dito, a possibilidade de se efetuar a qualificação jurídica de um determinado objeto.

Com a definição de contratos coligados apresentada acima, pode-se continuar para a organização desse conceito em categorias jurídicas. Nesse toar, a categoria "contratos" apresenta-se, quanto à coligação, como categoria alternativa e residual: existem contratos coligados e contratos não coligados, ou bem existe a coligação ou não. O tratamento jurídico a ser dado a contratos coligados difere do tratamento jurídico a ser conferido a contratos não coligados, pois categorias jurídicas distintas possuem regime jurídico diferente. Quando o operador do direito se depara com um conjunto de negócios jurídicos, a operação de qualificar a categoria jurídica aplicável a tais negócios se dá por meio de princípios da lógica clássica: no caso de coligação contratual, o contrato não pode ser simultaneamente coligado e não coligado (nenhum objeto pode ser, ao mesmo tempo, $\mathrm{P}$ e não-P, aplicação do princípio da não-contradição) e os contratos somente podem ser coligados ou não coligados (todo objeto tem que ser, necessariamente, $\mathrm{P}$ ou não-P,

\footnotetext{
${ }^{28}$ GOMES, Orlando. Introdução ao Direito Civil. Rio de Janeiro: Forense, 2016, p. 67.

${ }^{29}$ LOSANO, Mario. Sistema e estrutura no Direito. v. 2. São Paulo: Martins Fontes, 2010, p. 3.17
} 


\section{Personalidade Acadêmica Homenageada: \\ Florisbal de Souza Del'Olmo (Professor Convidado - UNICURITIBA)}

aplicação do princípio do terceiro excluído). ${ }^{30}$ Essa operação de qualificação é essencial, posto que os contratos coligados não podem ser interpretados como contratos simples, mas precisam ser interpretados de modo que essa sua complexidade seja levada em consideração.

O objetivo principal da qualificação jurídica é delimitar o regime jurídico a que se submeterá o objeto examinado. No caso dos contratos coligados, esse regime jurídico traz consigo um determinado modelo de interpretação jurídica. Para qualificar, o intérprete analisará o objeto jurídico a ser examinado e verificará a presença dos elementos distintivos constantes do conceito de contratos coligados (elementos E1, E2 e E3 apresentados anteriormente). Identificados os elementos distintivos, o intérprete poderá estabelecer se está diante de um contrato coligado e, caso esteja, dar continuidade à tarefa interpretativa.

Como os contratos coligados são normalmente celebrados por uma multiplicidade de instrumentos contratuais, tais como contratos, termos, escrituras, é essencial que o método de interpretação vise à coerência das disposições internas dos contratos. Após a qualificação jurídica, que requer uma definição segura do objeto submetido à intepretação, a análise da coerência interna dos contratos leva à busca pela harmonização das disposições contratuais.

Essa busca pela coerência interna ocorre, no caso dos contratos coligados, em duas direções: a) coerência vertical, num processo mediante o qual se busca ver se as disposições de um contrato estão em harmonia com as disposições de um mesmo contrato; b) coerência horizontal, num processo mediante o qual se busca analisar se as disposições de um determinado contrato estão em harmonia com as disposições dos demais contratos coligados.

O método interpretativo a ser adotado para interpretações de contratos coligados é um método lógico-sistemático por excelência, visto que a exigência de coerência interna e o afastamento de contradições conduzem a uma análise lógica e a necessidade de cotejo das disposições contratuais e destas com a legislação leva a uma análise sistemática. Não basta apenas buscar a coerência interna num único

\footnotetext{
${ }^{30}$ Cf. MAYNEZ, Eduardo Garcia. Introduccion a la Logica Juridica. Cidade do México: Fondo de Cultura Economica, 1951, passim.
} 


\section{Personalidade Acadêmica Homenageada: \\ Florisbal de Souza Del'OImo (Professor Convidado - UNICURITIBA)}

instrumento contratual: é preciso ainda que essas disposições se harmonizem com a dos demais instrumentos contratuais, numa movimentação interpretativa tanto vertical como horizontal. Essa coerência interna nada mais é que a aplicação do princípio lógico-jurídico da não contradição, expressado por Garcia Maynez nos seguintes termos: "duas normas de direito contraditórias entre si não podem ambas ser válidas" ${ }^{31} \mathrm{O}$ seja, se ao proceder à interpretação de um determinado contrato coligado o intérprete se deparar com duas disposições contraditórias, é de se entender que ambas não podem ser válidas e caberá ao intérprete estabelecer qual deverá prevalecer.

O problema desse modelo é que a necessidade de se manter apenas uma das disposições não dá um critério para escolher qual delas deve ser aplicada. Para tanto, ele precisará se valer dos critérios de solução de antinomias. Os critérios clássicos de resolução de antinomias (especialidade, cronologia e hierarquia) também não parecem ser suficientes para escolher qual a determinação que deve prevalecer. Elas poderão ser usadas, e serão, sobretudo quando se trata de aplicação de disposições legais, mas quando se trata de provisão contratual, o horizonte parece ser mais confuso.

Por exemplo, uma determinada empresa celebra com um consórcio de bancos um contrato de financiamento, fazendo parte da coligação um instrumento de constituição do consórcio, o contrato de financiamento propriamente dito, as escrituras de constituição de hipoteca, os termos de alienação fiduciária e de penhor mercantil. O contrato de financiamento prevê a possibilidade de decretação de vencimento antecipado se perecidos os bens objeto do penhor mercantil, enquanto $o$ termo de constituição do penhor admite a possibilidade de substituição dos bens apenhados por outros de igual espécie, na hipótese de perecimento. Trata-se, aqui, de um caso em que o interprete deve fazer um exame de coerência horizontal e afastar a contradição entre o disposto no contrato de financiamento e o disposto no termo de constituição do penhor.

\footnotetext{
${ }^{31}$ MAYNEZ, Eduardo Garcia.op. cit. p. 169.
} 


\section{Personalidade Acadêmica Homenageada: \\ Florisbal de Souza Del'OImo (Professor Convidado - UNICURITIBA)}

Essas cláusulas estabelecem situações contraditórias: ou bem o devedor tem o direito de substituir os bens apenhados, sem que se processe o vencimento antecipado do contrato ou não o tem.

O intérprete precisa harmonizar essas disposições, sabendo desde já que ambas não podem simultaneamente prevalecer, não podem ambas serem ambas válidas. Os critérios clássicos de solução de antinomias também não parecem responder a essa questão, de modo que resta ao intérprete lançar mão de vetores hermenêuticos que possam harmonizar as disposições. Por vetor hermenêutico entende-se o preceito jurídico que indica a orientação a ser seguida pelo intérprete, quando da busca pelo definição e alcance das disposições contratuais. O vetor indica a direção e o sentido a ser perseguido pelo intérprete. Nesse sentido, não difere do que a doutrina costuma chamar de pautas de interpretação ${ }^{32}$

O próprio Código Civil já menciona o princípio da boa-fé e a probidade como norteadores das relações contratuais, bem como a prevalência da autonomia privada, mas parece que, no caso específico dos contratos coligados, construídos normalmente para se estabelecer relações de médio e longo prazo ${ }^{33}$, é possível ajuntar alguns outros vetores que ajudam a manter a coerência interna. Um desses vetores é justamente o da preservação das relações contratuais, de modo que, havendo confronto entre duas disposições, deverá prevalecer aquela que visa a manter a continuidade das relações contratuais, visto que o prolongamento no tempo é ínsito aos contratos coligados. No exemplo mencionado acima, deve-se

\footnotetext{
${ }^{32}$ Nesse sentido, Judith Martins-Costa considera a boa-fé como uma pauta de interpretação, um exemplo de cânone hermenêutico. A expressão vetor hermenêutico não é muito distante da expressão pauta de interpretação, ambas concebidas como orientadoras do processo interpretativo dos intérpretes. Prefere-se a expressão vetor hermenêutico pelo forte caráter orientativo que o termo vetor traz em si: vetores possuem sentido e direção. Assim, um vetor hermenêutico aponta o sentido e a direção que a interpretação deve tomar, enquanto que a expressão pauta de interpretação evoca a ideia de uma lista de temas a serem usados pelo intérprete. A questão, enfim, é mais de preferência terminológica do que propriamente de diferença conceitual. Cf. MARTINS-COSTA, Judith. A boa-fé no Direito Privado: critérios para sua a sua aplicação. São Paulo: Marcial Pons, 2015, p. 42.

${ }_{33}$ Normalmente, os tipos contratuais mais comuns em contratos coligados são contratos cuja execução se prolonga no tempo, sendo espécies de contratos de duração. É assim com os contratos de financiamento, de distribuição, de locação, de cessão de marca, de empreitada. Dada a complexidade do fenômeno da coligação contratual, as partes buscam relações estáveis e duradouras, ainda que contratos instantâneos de execução imediata, como os de compra e venda, costumem compor as coligações contratuais.
} 


\section{Personalidade Acadêmica Homenageada: \\ Florisbal de Souza Del'OImo (Professor Convidado - UNICURITIBA)}

afastar a hipótese de vencimento antecipado, para permitir que o devedor substitua a garantia dada, preservando-se a relação contratual, em lugar de se reconhecer o vencimento antecipado. Apenas na hipótese de essa substituição não acontecer, poder-se-ia falar na aplicação do vencimento antecipado.

Além da preservação das relações contratuais, outro vetor hermenêutico aplicável aos contratos coligados é o do sentido econômico do contrato. O aspecto econômico, aqui, entra como elemento jurídico para fornecer ao intérprete critérios de como interpretar disposições contratuais em aparente antinomia. No exemplo dado anteriormente, o financiamento é o elemento econômico mais forte, de modo que o contrato de mútuo bancário firmado entre as partes pode ser considerado o elemento cerne dessa coligação, sendo os demais deles dependentes. Havendo conflito entre duas disposições, o elemento econômico pode ser utilizado como vetor hermenêutico, e as práticas bancárias correntes podem ser usadas como instrumentos para dirimição do conflito, de modo que a coerência interna dos contratos seja preservada.

Os contratos coligados, portanto, requerem um modelo de interpretação lógico-sistemática. Esse modelo começa pelo estabelecimento da definição de coligação contratual, de modo que o interprete possa realizar a operação de qualificação jurídica adequada. Uma vez realizada a qualificação jurídica e o contrato for qualificado como coligado, o método de interpretação a ser utilizado é o lógico-sistemático. Tal método busca analisar as disposições contratuais numa duplica coerência: a coerência vertical, em que as disposições de um único instrumento entre si são analisadas; e a coerência horizontal, em que as disposições de um contrato são analisadas em relação as disposições dos demais instrumentos contratuais integrantes da coligação.

Para a solução de conflitos, além da própria boa-fé e probidade, pode-se ajuntar dois vetores hermenêuticos: a necessidade de preservação dos contratos e a adoção do elemento econômico como critério para harmonização das disposições. Essa estrutura, no entanto, ainda não é suficiente para orientar o processo hermenêutico, posto que o intérprete pode deparar-se com situações que requeiram 


\section{Personalidade Acadêmica Homenageada:}

Florisbal de Souza Del'Olmo (Professor Convidado - UNICURITIBA)

o exame de legalidade das disposições contratuais ou o afastamento de antinomias jurídicas decorrentes de aplicação de legislação distintas.

\section{DUPLA SISTEMATICIDADE DOS CONTRATOS COLIGADOS: ANÁLISES MICRO E MACROSSISTÊMICA}

O exame de coerência interna dos contratos apresentado acima é apenas um dos eixos sistemáticos do modelo que se vem desenvolvendo aqui. Verificar a coerência interna, em seus sentidos vertical e horizontal, corresponde ao elemento microssistêmico dos contratos coligados. Além desse aspecto microssistêmico, há um outro, de caráter macrossistêmico, consistente no exame de legalidade das disposições dos contratos coligados. Esse exame de legalidade é particularmente complexo, pois é bastante comum que a coligação de contratos gere instrumentos contratuais regidos por legislações distintas.

Tomando-se o exemplo acima, em que a coligação contratual era constituída por um contrato de financiamento bancário, por um instrumento de constituição de consórcio, por escrituras públicas de constituição de hipoteca, por contrato de seguro e por termo de penhor mercantil, percebe-se de logo a dificuldade: regulam tais contratos o Código Civil, a legislação securitária, a lei de registros públicos, entre outros.

$\mathrm{Na}$ fase macrossistêmica da interpretação, serão duas as etapas empreendidas pelo intérprete: a) legalidade vertical: o intérprete verificará se uma disposição contratual está em dissonância com o que prevê a lei específica reguladora do contrato individualizado, não havendo, nesse primeiro momento, diferença substancial entre esse tipo de interpretação e o da interpretação de um contrato não coligado; b) legalidade horizontal: o intérprete verificará se as disposições contratuais, em seu conjunto, padecem de alguma ilegalidade. 


\section{Personalidade Acadêmica Homenageada:}

Florisbal de Souza Del'Olmo (Professor Convidado - UNICURITIBA)

Essa segunda fase pode parecer mais incomum, mas há casos muito específicos de coligação contratual em que o conjunto das disposições é que ofensivo à ordem jurídica.

Como exemplo desse tipo de situação, há as figuras dos planos de recuperação judicial de grupos empresários, normalmente compostos pelo plano de recuperação, propriamente dito, e formado por outros instrumentos contratuais que a ele se juntam de forma acessória. É frequente que entre esses instrumentos encontrem-se contratos internacionais, bonds, escrituras de emissão de debêntures, instrumentos de constituição de garantias, termos de alienação patrimonial com estipulação para compra do bem por parte dos acionistas, etc. Apenas a análise sistêmica dessas disposições permitirá ver se há alguma ilegalidade: a combinação da possibilidade de compra de um ativo por valor inferior por parte de um acionista associada a um deságio nas condições de financiamento pode desfavorecer minoritários e significar, por exemplo, enriquecimento sem causa.

Uma análise seca das disposições dos contratos, examinando-se apenas a legalidade daquele instrumento frente a lei que rege a categoria jurídica específica (por exemplo, usar a legislação reguladora da cessão fiduciária para examinar uma cessão), não permitirá que se perceba ilegalidades extraídas do conjunto das disposições contratuais.

Numa outra situação de coligação contratual, um contrato de distribuição associado a um contrato de cessão de marca pode, cada um, estabelecer obrigações que, isoladamente, seriam consideradas lícitas. No entanto, acaso combinadas, podem gerar uma situação de onerosidade excessiva. Ora, a figura da onerosidade excessiva normalmente é analisada examinando-se exclusivamente um único contrato; nas hipóteses de coligação, essa onerosidade pode decorrer do conjunto das disposições. A exceção de contrato não cumprido, por exemplo, também pode ser alegada em função do conjunto de contratos coligados, e não de um deles isoladamente. Percebe-se, portanto, que a análise macrossistêmica tem importante papel não só no controle hermenêutico, mas igualmente no controle de legalidade dos instrumentos contratuais. 


\section{Personalidade Acadêmica Homenageada:}

Florisbal de Souza Del'Olmo (Professor Convidado - UNICURITIBA)

\section{CONCLUSÕES}

No decorrer do presente trabalho, tentou-se descrever um modelo de interpretação jurídica que permita aos intérpretes melhor trabalhar os problemas dos contratos coligados. Após discussão sobre a evolução, natureza, classificação e tratamento jurisprudencial dada ao fenômeno da coligação contratual, buscou-se desenvolver um modelo lógico-sistemático de interpretação de contratos coligados, constituído dos seguintes passos:

1) Qualificação jurídica:

a) Partindo-se da definição de coligação contratual, e dos seus elementos distintivos, identificar se uma determinada situação é caso de coligação ou não;

2) Análise microssistêmica

b) Análise de coerência interna vertical: verificar se as disposições de um determinado contrato encontram-se harmônicas entre si; c) análise de coerência horizontal: verificar se as disposições de um determinado contrato encontram-se em harmonia com as disposições dos demais contratos integrantes da coligação;

3) Análise macrossistêmica

c) Análise vertical: verificar se as disposições de um determinado contrato integrante da coligação colidem com as disposições da lei que regula aquele tipo participar de contrato; d) Análise horizontal: verificar se o conjunto das disposições dos contratos coligados colide com as disposições do ordenamento jurídico.

Nesse modelo esboçado, a fase mais crítica é, sem dúvida, a da análise macrossistêmica, visto que o intérprete terá o trabalho de analisar o conjunto das disposições, para verificar alguma ofensa ao ordenamento. A maior vantagem do modelo de interpretação é orientar o intérprete e permitir que ele analise as disposições contratuais de modo a explorar toda a riqueza de situações jurídicas decorrentes do fenômeno da coligação. 


\section{Personalidade Acadêmica Homenageada:}

Florisbal de Souza Del'Olmo (Professor Convidado - UNICURITIBA)

Como qualquer modelo, ajustes ainda se farão necessários e outros pontos precisarão ser examinados. O problema das lacunas e da integração, por exemplo, não chegou a ser abordado aqui e exige um capítulo à parte.

Outro ponto a ser explorado é o dos efeitos da invalidade contratual. Se se levar em conta que a fase macrossistêmica permite que vícios e exceções possam ser opostas ao conjunto de contratos coligados, é fácil perceber que o problema da invalidade contratual seguirá o mesmo caminho e se poderá ter uma nulidade decorrente do conjunto dos contratos coligados. Tais temas não chegaram a ser abordados no presente trabalho, mais são merecedores de trabalhos futuros, de modo que se possa, aos poucos, ter um modelo e uma teoria mais consistentes a respeito do fenômeno da coligação contratual.

\section{REFERÊNCIAS}

DONNINI, Rogério. Responsabilidade civil na pós-modernidade: felicidade, proteção, enriquecimento com causa e tempo perdido. Porto Alegre: Sérgio Antônio Fabris Ed., 2015.

GOMES, Orlando. Contratos. Rio de Janeiro, Forense, 1998.

LEONARDO, Rodrigo Xavier. Contratos coligados, redes contratuais e contratos conexos. In: FERNANDES, Wanderley (coord). Contratos Empresariais: fundamentos e princípios dos contratos empresariais. São Paulo: Saraiva, 2012.

LOSANO, Mario. Sistema e estrutura no Direito. v. 2. São Paulo: Martins Fontes, 2010.

MARINO, Francisco de Paula De Crescenzo. Contratos Coligados no direito brasileiro. São Paulo: Saraiva, 2009.

MARQUES, Claudia Lima. Contratos no Código de Defesa do Consumidor: o novo regime das relações contratuais. 5. ed. São Paulo: Editora Revista dos Tribunais, 2005.

Contratos Bancários em tempos pós-modernos: primeiras reflexões. Revista de Direito do Consumidor, São Paulo: Ed. Revista dos Tribunais, v. 25, p. 19-38, jan/mar, 1998. 
Personalidade Acadêmica Homenageada:

Florisbal de Souza Del'Olmo (Professor Convidado - UNICURITIBA)

MARTINS-COSTA, Judith. A boa-fé no Direito Privado: critérios para sua a sua aplicação. São Paulo: Marcial Pons, 2015.

MAYNEZ, Eduardo Garcia. Introduccion a la Logica Juridica. Cidade do México: Fondo de Cultura Economica, 1951

MIGUEL, Paula Castello. Contratos entre empresas. São Paulo: Editora Revista dos Tribunais, 2006.

NANNI, Giovanni Ettore. A evolução do direito civil obrigacional: A concepção do direito civil constitucional e a transição da autonomia da vontade para a autonomia privada. In: Cadernos de Direito Civil Constitucional. Renan Lotufo (coord. ). 1 $1^{\text {a }}$ ed. (2001) 8a reimpressão. Curitiba. Juruá, 2008.

ROPPO, Enzo. O contrato. Lisboa: Editora Almedina, 2009. 